\title{
Intranasal Delivery of Two Benzodiazepines, Midazolam and Diazepam, by a Microemulsion System
}

\author{
Shafir Botner, Amnon C. Sintov* \\ Department of Biomedical Engineering, Faculty of Engineering Sciences, Ben Gurion University of the Negev, Beer Sheva, Israel. \\ Email: asintov@bgu.ac.il
}

Received January $2^{\text {nd }}, 2011$; revised May $4^{\text {th }}, 2011$; accepted June $23^{\text {th }}, 2011$.

\begin{abstract}
Nasal application of benzodiazepines might be an alternative to intravenous administration in acute clinical situations such as seizures emergencies. However, irritation and pain as well as symptoms like teary eyes, dizziness, discomfort, nasal drainage and bad taste usually accompany subject received midazolam and diazepam via the nasal route. The purpose of this study was to evaluate the use of a new alcohol-free microemulsion system as a carrier for diazepam or midazolam given intranasally. Midazolam (base) or diazepam was solubilized in the microemulsion to obtain a high drug concentration of $25 \mathrm{mg} / \mathrm{g}(2.5 \%$ by weight $)$, to provide $2.5 \mathrm{mg}$ drug in $100 \mathrm{\mu l}$ spray $(\mathrm{d} \approx 1.00 \mathrm{~g} / \mathrm{ml})$. The nasal absorption of both drugs from the same microemulsion formulation (containing $20 \%$ aqueous phase) was found to be fairly rapid after administration of $0.4 \mathrm{mg} / \mathrm{kg}$ to rabbits. The absolute bioavailability of diazepam after intranasal administration using this formulation was $33.45 \% \pm 12.36 \%$ and the $t_{\max }$ was $18.33 \pm 23.09$ min, which was twice longer than the $t_{\max }$ obtained after midazolam administration, $9.25 \pm 6.75 \mathrm{~min}$. The pharmacokinetic parameters of midazolam in W/O (20\% water) microemulsion and their comparison with midazolam in $\mathrm{O} / \mathrm{W}(50 \%$ water) microemulsion have shown that both formulations resulted in a relatively short time to reach the peak plasma level $\left(t_{\text {max }}\right)$, that is, $9.25 \pm 6.75$ min and $6.75 \pm 5.67 \mathrm{~min}$, respectively. However, the peak plasma levels $\left(C_{\max }\right)$ and the absolute bioavailability $\left(F_{A}\right)$ of midazolam were significantly higher after administration of the W/O formulation than those obtained after application of $\mathrm{O} / \mathrm{W}$ formulation, i.e., $46.62 \pm 17.38 \mu \mathrm{g} / \mathrm{ml} \mathrm{vs} .15 .44 \pm 4.00 \mu \mathrm{g} / \mathrm{ml}$, and $35.19 \% \pm 11.83 \% \mathrm{vs} .19 .83 \% \pm 16.32 \%$, respectively. Our results suggest that the new microemulsion system may be useful for getting rapid-onset of midazolam and diazepam following intranasal administration, resulting in reasonable peak plasma levels and bioavailability, but most importantly, providing a high measure of tolerability and comfort.
\end{abstract}

Keywords: Microemulsion, Intranasal Drug Delivery, Benzodiazepines, Nasal Spray, Diazepam, Midazolam

\section{Introduction}

Benzodiazepines are a group of psychoactive drugs with clinical effects like sedation, hypnotic, anxiolytic, anticonvulsant, muscle relaxant and amnesia. These therapeutic properties make benzodiazepines useful in treating anxiety, insomnia, agitation, seizures, muscle spasms, alcohol withdrawal syndrome and as a premedication for various medical or dental procedures. Benzodiazepines have been the first line treatment of seizures, which are an emergency medical situation [1]. While untreated prolonged seizures increase the risk of mortality, morbidity and permanent brain damage, an early and rapid termination of the seizures by benzodiazepines is needed. Benzodiazepines exert their anticonvulsant effect by in- teracting with $\gamma$-aminobutric acid (GABA) receptors at the benzodiazepine binding site and allosterically modifying $\mathrm{GABA}_{\mathrm{A}}$ receptor current to enhance inhibition [24].

Traditionally, intravenous and especially rectal diazepam (DZP), a highly lipophilic benzodiazepine, has been used as front line therapy. However, diazepam via intravenous and rectal routes have several drawbacks [58]: 1) The establishment of an intravenous access is not practical in an emergency situation when the patient is not in a hospital. A highly qualified, trained medical person is required for this procedure; 2) The use of rectal diazepam results in variable plasma levels and fails to terminate $30 \%$ of seizures [9]. It is also socially embarrassing, and although difficult to administer during con- 
vulsions can be used only in children and in a few cases in adolescents; 3) it is highly lipophilic and therefore has a large volume of distribution. Repeated doses are sometime needed and its accumulation may lead to complications such as bradypnea and even respiratory arrest $[10,11]$. Diazepam is also available in tablets; however, the oral route is not accessible during seizures and cannot be used. Thus, an alternative fast-acting benzodiazepine delivery route, such as the nasal route, is needed. By the alternative route, diazepam should be easily administered by the surrounding people or caregivers and could dramatically improve the management of out-of-hospital seizures as well as the patient recovery. The intranasal administration of diazepam was evaluated in several studies, in which supersaturated formulations were used with solvents such as a glycofurol/water mixture [7,12], glycofurol/polyethylene glycol 200 [13,14], propylene glycol/ethanol [15], and polyethylene glycol 300 [16]. Human studies $[7,12]$, which were conducted on human volunteers reported that subjects rated nasal diazepam as causing considerable pain immediately following administration. In addition, discomfort, nasal drainage and watery eyes were also reported.

Midazolam hydrochloride (MDZ-HCl) is a short acting, water soluble benzodiazepine. Its effectiveness on the CNS is dependent on the dose, route of administration, and whether it is used concomitantly with other medications. Midazolam has also been used for rapid anesthesia at emergency setting and as an agent for sedation prior to medical procedures. Because of its high solubility in aqueous solutions, $\mathrm{MDZ}-\mathrm{HCl}$ can be used intravenously, intramuscularly, buccally, and intranasally. Although midazolam is marketed only in injectable and oral syrup formulations, there is increased interest in its administration via the nasal route and it is indeed the most extensively studied nasal benzodiazepine [17]. A survey research [18] among anesthesiologists showed that the most commonly used $(>80 \%)$ sedative premedicant in children was midazolam, $8 \%$ of which have practiced intranasal midazolam, apparently in "off-label" use, to premedicate pediatric patients preoperatively. The interest in intranasal drug delivery arises from the unique advantages presented by the nasal cavity such as: 1) A large surface area available for drug deposition and absorption, 2) The nasal epithelium is thin and highly vascularized, 3) Absorbed substances are transported directly into the systemic circulation thereby avoiding the first pass metabolic effect, and 4) In some cases, drug can be absorbed directly into the CNS by passing the tight blood brain barrier [19]. Intranasal midazolam has already been explored during the last decade and a number of clinical works revealed the potential of its administration via the nasal route [9-11,17,20-23]. Nev- ertheless, there are still issues waiting to be resolved. Most studies reported the use of various dilutions of a commercial midazolam, dripped by syringe into patient's nostrils. This use of aqueous solutions (usually employed for injections) is not optimal for intranasal administration from two main reasons: a) The acidic $\mathrm{pH}(\mathrm{pH} \approx 3)$ is too low for the nasal mucosal membrane and is therefore a potential irritant, and $b$ ) The solutions are too diluted to provide a considerably small volume for human nostril, namely, $100-150 \mu 1$ of liquid at a time. Optimal formulation should contain at least $2.5 \mathrm{mg}$ of midazolam in $100 \mu 1$ solution. Although more concentrated MDZ-HCl solutions $[17,21,26]$ resulted in a relatively high bioavailability in healthy volunteers, the researchers reported that irritation ("burning" sensation) and pain occurred in all subject received midazolam, as well as symptoms like teary eyes, dizziness, and bad taste.

In the present paper, we propose the use of a new microemulsion that in pre-clinical studies, seemed to have solved the problem of irritability following regular nasal benzodiazepine administrations. We have studied and compared the pharmacokinetic characteristics of diazepam and midazolam applied to rabbits in a microemulsion formulation via the nasal route. The new microemulsion system did not contain alcohols or other irritant chemicals and is generally recognized as safe (GRAS) compounds. The purpose of this work was to evaluate the use of the new microemulsion formulation as a carrier for diazepam or midazolam given via the nasal route.

\section{Materials and Methods}

\subsection{Materials}

Midazolam (base) and diazepam were kindly donated by Rafa Laboratories Ltd., Jerusalem, Israel. Commercial midazolam $\mathrm{HCl}$ solution for injection (Midolam amps., 5 $\mathrm{mg} / \mathrm{ml}$ or $0.5 \% \mathrm{wt} / \mathrm{v}$, Rafa Laboratories, Israel) was purchased from a local pharmacy. Commercial diazepam solution for injection (Assival amps., $10 \mathrm{mg} / 2 \mathrm{ml}$, Teva Group, Israel) was also purchased from a local pharmacy. Glyceryl oleate was obtained from Uniqema, Bromborough Pool, The Wirral, UK. Labrasol was obtained from Gattefosse, France. Isopropyl palmitate (IPP) and propylene carbonate were purchased from Aldrich (SigmaAldrich Inc., St. Louis, MO). Acepromazine $(10 \mathrm{mg} / \mathrm{ml}$ acepromazine maleate) was used from PromAce Injectable, Fort Dodge-Animal Health (Iowa, USA).

\subsection{Preparation of Microemulsions}

Generally, microemulsions were prepared by mixing Labrasol, glyceryl oleate (surfactants) and isopropyl palmitate (oil) with propylene carbonate (co-surfactant) and water. Appropriate quantities of midazolam (base) or di- 
azepam were then solubilized in the microemulsion to reach a final concentration of $2.5 \%(\mathrm{wt} / \mathrm{wt})$ of the desired drug. The monophasic formulations were formed after a short stirring at room temperature. The cosurfactantsurfactants $(\mathrm{CoS} / \mathrm{S})$ weight ratio was $1: 5$, and the surfactants; ratio was $1: 3$.

\subsection{Construction of Phase Diagrams}

Pseudo-ternary phase diagrams of oil, distilled water, and co-surfactant $(\mathrm{CoS})$ - surfactants $(\mathrm{S})$ mixtures were constructed at fixed $\mathrm{CoS} / \mathrm{S}$ weight ratios. The weight ratio of the two surfactants, glyceryl oleate to Labrasol derivative, were fixed and kept constant. Phase diagrams were obtained by visual inspection of mixtures of the ingredients, which were pre-weighed into glass vials, titrated with water and stirred well at room temperature. As a convenient method, the construction of the phase diagrams were done by drawing "water dilution lines" representing an increase of water content while decreasing CoS-S and oil levels. The water was titrated along dilution lines drawn from the water apex to the opposite surfactant side of the triangle. The line was arbitrarily denoted as the value of the line intersection with the surfactant scale (e.g., DL87 means line representing a surfactant-to-oil ratio of $87: 13$ ). In case turbidity appeared followed by a phase separation, the samples were considered as biphasic. In case monophasic, clear and transparent mixtures were visualized, the samples were marked as points in the phase diagram. The area covered by these points was considered as the microemulsion region of existence.

\subsection{Dynamic Light Scattering (DLS)}

The hydrodynamic diameter spectrum of microemulsion nano-droplets was collected using CGS-3 Compact Goniometer System (ALV GmbH, Langen, Germany). The laser power was $20 \mathrm{~mW}$ at the He-Ne laser line $(632.8$ $\mathrm{nm})$. Correlograms were calculated by ALV/LSE 5003 correlator, which were collected at $60^{\circ}$, during $10 \mathrm{~s}$ for 20 times, at $25^{\circ} \mathrm{C}$. Measurements were performed at permanent angle of $60^{\circ}$. The droplet size was calculated using the Stokes-Einstein relationship, and the analysis was based on regularization method as described by Provencher [24].

\subsection{Pharmacokinetic Study}

All animal procedures were performed in accordance with protocols reviewed and approved by the Institutional \& Use Committee, Ben Gurion University of the Negev, which complies with the Israeli Law of Human Care and Use of Laboratory Animals. New Zealand white rabbits (HsdIf: NZW males, 2.0 - $3.5 \mathrm{~kg}$ body weight, Harlan, Jerusalem) were used in the experiments.
The rabbits were housed individually with free access to food and water. A $12 \mathrm{~h}$ light/12 $\mathrm{h}$ dark cycle was held to keep a normal circadian rhythm in the animals. Nasal formulations or intravenous drug dosage forms were administered in a randomized cross-over design with a wash-out period of at least four days. After the animals had been tranquillized with $0.5 \mathrm{ml}$ acepromazine, Venflon $^{\mathrm{TM}}$ cannula (22 G, Poly Medicure Ltd., Faridabad, India) was inserted into the main artery of the rabbit ear. Each rabbit was weighed and the drug (MDZ or DZP) was nasally or intravenously administered. Microemulsion containing $2.5 \% \mathrm{wt} / \mathrm{wt}(=25 \mathrm{mg} / \mathrm{g})$ midazolam or diazepam was administered at a $0.4 \mathrm{mg} / \mathrm{kg}$ dose by nasal spraying (approx. $100 \mu \mathrm{l}$ of microemulsion containing $2.5 \mathrm{mg}$ of drug, approx. $50 \mu \mathrm{l}$ in each nostril). For the purpose of comparison, MDZ at the same dosage was also applied in macro-emulsion formulation (same formulation without co-surfactant) and in a mixture of oil and surfactants (same formulation without an aqueous phase), all based on the same microemulsion's components and their ratios. Commercial midazolam solution for injection $(5 \mathrm{mg} / \mathrm{ml})$ had first been diluted in sterile saline solution $(\times 5)$ before administered intravenously at a $0.2 \mathrm{mg} / \mathrm{kg}$ dose (approx. $0.5 \mathrm{ml}$ solution). Commercial diazepam solution for injection $(5 \mathrm{mg} / \mathrm{ml})$ had first been $\times 5$ diluted in propylene glycol then administered intravenously at a $0.2 \mathrm{mg} / \mathrm{kg}$ dose (approx. $0.5 \mathrm{ml}$ solution). The exact application volume was determined according to the individual body weight. Spraying technique was developed by using a $100 \mu \mathrm{l}$ syringe connected to MAD Nasal Drug Delivery Device (MAD 320, Wolfe Tory Medical, Inc., Salt Lake City, UT). Blood samples were collected at $0,2,5,15,30,45,60,90,120$, and $180 \mathrm{~min}-$ utes after application in heparin-containing tubes. Plasma was obtained after centrifugation at $10,000 \mathrm{rpm}$ for 10 minutes, and stored at $-20^{\circ} \mathrm{C}$ until analyzed for $\mathrm{MDZ}$ or DZP. Plasma drug concentrations were determined using LC /MS/MS method pre-developed in our laboratory.

\subsection{Plasma Drug Determination}

A LC/MS/MS analysis was performed using a Reprosil C18-AQ $5 \mu \mathrm{m}$ column $(100 \times 2 \mathrm{~mm})$ (Dr. Maisch, Germany), equipped with a $\mathrm{C}_{18}$ guard column. The mobile phase consisted of a 33.3:66.7 v/v mixture of $1 \mathrm{mM}$ ammonium acetate buffer (eluent $\mathrm{A}$ ) and methanol-acetonitrile $(20: 80 \mathrm{v} / \mathrm{v})$ (eluent $\mathrm{B})$. The flow rate was $0.3 \mathrm{ml} / \mathrm{min}$ at ambient temperature. Detection was performed using an API 2000 instrument (MDX SCIEX, Concord, Ontario, Canada). The API 2000 ES source was tuned by infusing a standard solution of drug $(1 \mu \mathrm{g} / \mathrm{ml}$ in methanol $)$ into the source at a flow rate of $10 \mu \mathrm{L} / \mathrm{min}$. The optimal parameters were: source temperature $550^{\circ} \mathrm{C}$, declustering potential $96 \mathrm{eV}$, focusing potential $370 \mathrm{eV}$, entrance 
potential $12 \mathrm{eV}$, collision energy $37 \mathrm{eV}$, and collision cell exit potential (CXP) $4 \mathrm{eV}$. The spectrometer was used in the MS/MS mode with MRM of fragmentation reactions selected for each drug. Positive ion mode was used, and selected-ion monitoring was accomplished at $\mathrm{m} / \mathrm{z} 326$ for MDZ and m/z 285 for DZP. Quantitative on-line HPLC-ESI-MS/MS analyses were performed using an Analyst Software system interfaced to an Applied Biosystems API2000 instrument (Foster City, CA, USA).

\subsection{Data Analysis}

All pharmacokinetic parameters, i.e., peak plasma level $\left(\mathrm{C}_{\max }\right)$, time to reach peak plasma level $\left(t_{\max }\right)$, elimination terminal slope $\left(\lambda_{\mathrm{z}}\right)$, half-life of elimination $\left(t_{1 / 2}\right)$, were obtained after analysis of the individual time-plasma concentrations by WinNonlin Professional software version 5.2.1 (Pharsight Corporation, Mountain View, CA), using a non-compartmental model. The area under the plasma concentration of midazolam or diazepam versus time curve $\left(\mathrm{AUC}_{0 \rightarrow \infty}\right)$ was calculated using the linear trapezoidal rule and extrapolated to infinity by adding the last measurement of plasma concentration divided by the terminal slope $\left(\mathrm{C}_{\text {last }} / \lambda_{z}\right)$. The nasal bioavailability of midazolam and diazepam was relative to intravenous administration done in the same animal normalized to dose.

\section{Results and Discussion}

We first examined the immediate response of four conscious rabbits to midazolam in microemulsion formulation $(2.5 \%)$ compared to a plain aqueous solution of midazolam hydrochloride $(0.5 \%)$. In a cross-over method, aliquots $(500 \mu \mathrm{l})$ of each formulation were sprayed into one nostril and the animals were carefully observed. All animals responded to the aqueous solution application in a wild behavior, mainly by shaking their heads and making sounds of distress. This response was ceased after a few minutes. In addition, a temporary swelling was observed around the nostril, where the drug had been applied. The swelling lasted for about 30 - 60 minutes. In comparison, no visual sign of an irritative response was noted after a similar volume application of a 5-fold higher concentration of the drug given in the microemulsion.

To characterize the microemulsion system we constructed a phase diagram and measured the droplet size of the inner phase. By constructing a phase diagram it is easier to determine the range of concentrations and the ratios of components in the existence region of microemulsion. A pseudo-ternary phase diagram at a $\mathrm{CoS} / \mathrm{S}$ weight ratio of 1:5 is shown in Figure 1. As seen, in compositions containing more than $10 \%$ oil, the maximal

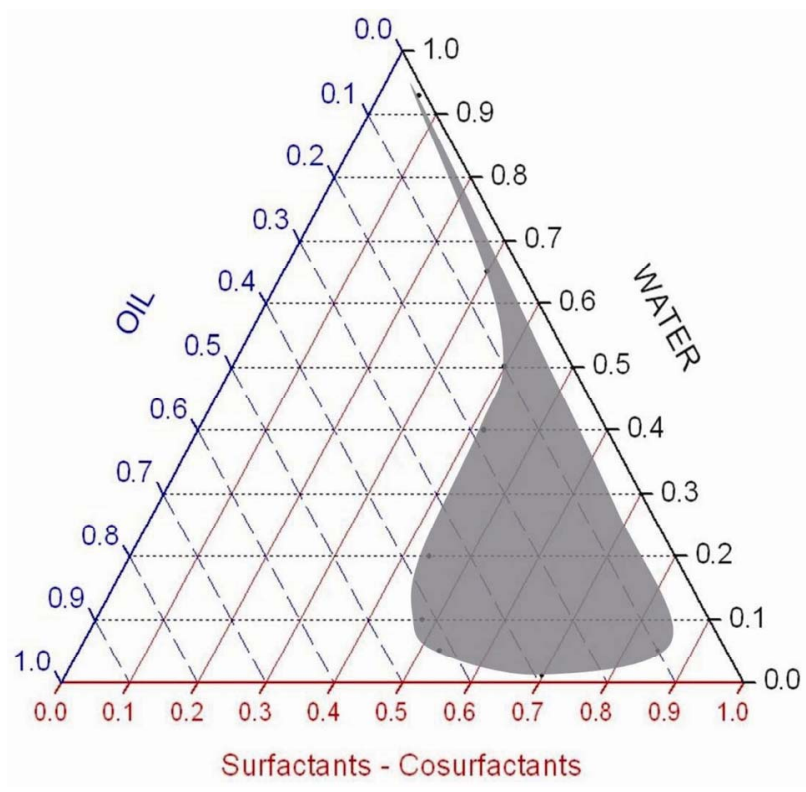

Figure 1. Pseudo-ternary phase diagram of a microemulsion system (shaded area) made of isopropyl palmitate (oil), glyceryl oleate and Labrasol (as surfactants at a 1:3 w/w ratio), propylene carbonate (co-surfactant) and water. The co-surfactant/surfactant ratio was 1:5.

water solubilization capacity of this microemulsion system is $50 \%$. Decreasing water content below $50 \%$ enables an incorporation of more isopropyl palmitate into the microemulsion. The average droplet size of drugunloaded microemulsion containing $20 \%$ water (surfactants-to-oil ratio $=87: 13)$ was $2 \mathrm{~nm}$ in diameter $(99.7 \%$ of total droplets). Our previous studies using this microemulsion system showed that loading of drug molecules and even of protein drugs into the nano-droplets did not much change the average droplet size [25].

The drug (midazolam base or diazepam) was solubilized in the microemulsion to obtain a final concentration of $25 \mathrm{mg} / \mathrm{g}(2.5 \%$ by weight), to provide $2.5 \mathrm{mg}$ drug in $100 \mu \mathrm{l}$ spray $(d \approx 1.00 \mathrm{~g} / \mathrm{ml})$. The microemulsion formulation of choice used for the pharmacokinetic studies contained $20 \%$ aqueous phase for the nasal delivery of both midazolam and diazepam. As presented in Table 1, a formulation containing $20 \%$ aqueous phase was chosen due to an achievement of a higher bioavailability compared with a formulation containing $50 \%$ aqueous phase. The influence of the quantity of the water phase on drug absorption may be due to changes occurring in the interfacial membrane's characteristics of the system, such as micellar inversion (W/O to $\mathrm{O} / \mathrm{W}$ and vice versa) and a possible change in the number of surfactant layers in which the drug is entrapped. Figure 2 illustrates schematically how inversion from $\mathrm{O} / \mathrm{W}$ to $\mathrm{W} / \mathrm{O}$ microemulsion can affect the drug accessibility to free diffusion 
Table 1. Mean pharmacokinetic parameters of midazolam after $I V$ and $I N$ administration to rabbits (total of 8 animals).

\begin{tabular}{|c|c|c|c|c|}
\hline \multirow[b]{2}{*}{ PK parameter } & \multicolumn{2}{|c|}{ Study $1, \mathrm{n}=4$ (paired) } & \multicolumn{2}{|c|}{ Study $2, \mathrm{n}=4$ (paired) } \\
\hline & IV solution ${ }^{*} 0.2 \mathrm{mg} / \mathrm{kg}$ & $\begin{array}{l}\text { IN microemulsion with } \\
20 \% \text { water } 0.4 \mathrm{mg} / \mathrm{kg}\end{array}$ & IV solution $^{* *} 0.2 \mathrm{mg} / \mathrm{kg}$ & $\begin{array}{l}\text { IN microemulsion with } \\
\mathbf{5 0 \%} \text { water } 0.4 \mathrm{mg} / \mathrm{kg}\end{array}$ \\
\hline $\begin{array}{c}\mathrm{C}_{\max }(\mu \mathrm{g} / \mathrm{ml}) \\
t_{\max }(\min )\end{array}$ & $\begin{array}{c}188.80( \pm 79.63) \\
0\end{array}$ & $\begin{array}{c}46.62( \pm 17.38) \\
9.25( \pm 6.75)\end{array}$ & $195.87( \pm 37.43)$ & $15.44( \pm 4.00)$ \\
\hline$\lambda_{z}\left(\min ^{-1}\right)$ & $0.0207( \pm 0.0035)$ & $0.0169( \pm 0.0041)$ & $0.0394( \pm 0.0145)$ & $0.0338( \pm 0.0158)$ \\
\hline Elimination $t_{1 / 2}(\min )$ & $34.19( \pm 5.88)$ & $43.15( \pm 11.63)$ & $19.57( \pm 7.24)$ & $28.32( \pm 22.86)$ \\
\hline $\mathrm{AUC}_{0-\infty}\left(\mu \mathrm{g} \cdot \mathrm{min} \cdot \mathrm{ml}^{-1}\right)$ & $3499( \pm 991)$ & $2494( \pm 1098)$ & $2050( \pm 334)$ & $789( \pm 607)$ \\
\hline $\mathrm{AUC}_{0-\infty} / \operatorname{dose}\left(\mu \mathrm{g} \cdot \mathrm{min} \cdot \mathrm{ml}^{-1} \cdot \mathrm{D}^{-1}\right)$ & $17.50( \pm 4.95)$ & $6.23( \pm 2.74)$ & $10.25( \pm 1.67)$ & $1.97( \pm 1.51)$ \\
\hline $\mathrm{F}_{\mathrm{A}}^{\mathrm{a}}(\%)$ & ---- & $35.19( \pm 11.83)$ & ---- & $19.83( \pm 16.32)$ \\
\hline
\end{tabular}

"IV reference group for the IN group which received $20 \%$ water-containing microemulsion; ${ }^{* *}$ IV reference group for the IN group which received $50 \%$ water-containing microemulsion; ${ }^{\mathrm{a}} \mathrm{F}_{\mathrm{A}} \%=$ absolute bioavailability $=\left(\mathrm{AUC}_{0-\infty}{ }^{\mathrm{IN}} \times \mathrm{Dose}^{\mathrm{IV}}\right) \times 100 /\left(\mathrm{AUC}_{0-\infty}{ }^{\mathrm{IV}} \times \mathrm{Dose}^{\mathrm{IN}}\right)$.
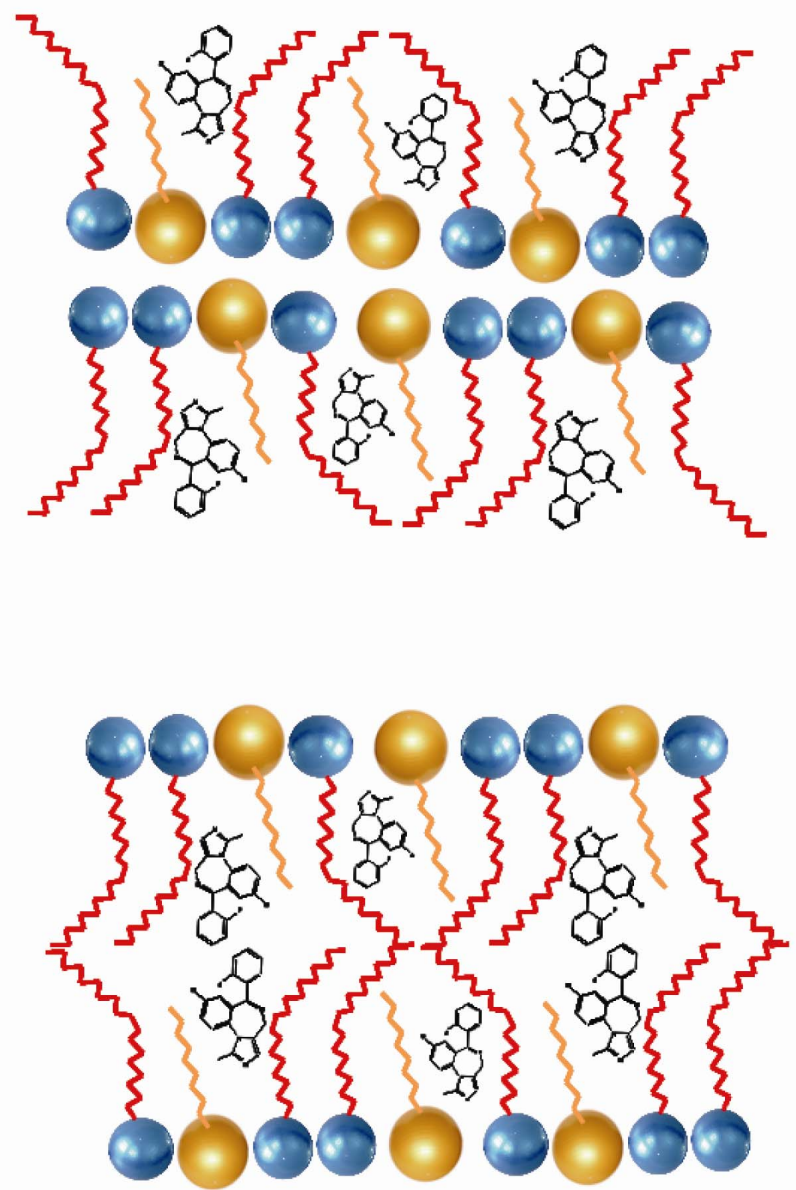

Figure 2. Schematic illustration (not to scale) of possible packing of midazolam in the nano-droplet's membrane; up: W/O microemulsion; bottom: $\mathrm{O} / \mathrm{W}$ microemulsion.

from the interfacial membrane to the outer phase. The pharmacokinetic parameters of midazolam in W/O $(20 \%$ water) microemulsion (Study 1) and their comparison with midazolam in $\mathrm{O} / \mathrm{W}(50 \%$ water $)$ microemulsion (Study 2) is presented in Table 1. As shown, both for- mulations resulted in a relatively short time to reach the peak plasma level $\left(t_{\max }\right), 9.25 \pm 6.75 \mathrm{~min}$ and $6.75 \pm 5.67$ min ( $t$-test, $p>0.05)$, respectively. In contrast, the peak plasma levels $\left(\mathrm{C}_{\max }\right)$ and the absolute bioavailability $\left(\mathrm{F}_{\mathrm{A}}\right)$ of MDZ were significantly higher after administration of the $\mathrm{W} / \mathrm{O}$ formulation than those obtained after application of $\mathrm{O} / \mathrm{W}$ formulation, i.e., $46.62 \pm 17.38 \mathrm{~g} / \mathrm{ml}$ vs. $15.44 \pm 4.00 \mu \mathrm{g} / \mathrm{ml}$, and $35.19 \% \pm 11.83 \%$ vs. $19.83 \% \pm$ $16.32 \%$, respectively $(p<0.05)$. It is to be noted that the average elimination half-life $\left(t_{1 / 2}\right)$ of MDZ in rabbits of Study 1 (Table 1) after IV administration was statistically different compared with the average value obtained after IV administration to rabbits of study 2, i.e., $34.19 \pm$ $5.88 \mathrm{~min}$ vs. $19.57 \pm 7.24 \mathrm{~min}$ ( $t$-test, $p<0.05$ ), respectively. This difference was probably due to the relatively lower body weight of the animals in study 2 . However, there was no statistically significant change in the halflives obtained after IN administration to the same animals in each study. In addition, no statistical difference was noted between half-lives of MDZ after IN administrations in both studies. Table 2 presents the pharmacokinetic parameters of diazepam in a study involved three rabbits which received both IV and IN administrations. Figures $\mathbf{3}$ and $\mathbf{4}$ show the pharmacokinetic profiles of $0.4 \mathrm{mg} / \mathrm{kg}$ doses of MDZ (Figure 3) and DZP (Figure 4) applied intranasally to rabbits as compared to IV administrations of each drug at $0.2 \mathrm{mg} / \mathrm{kg}$ doses. The nasal administration of both drugs was carried out by the same microemulsion vehicle containing $20 \%$ aqueous phase and $25 \mathrm{mg} / \mathrm{ml}$ drug concentration. As shown in Table 2, the absolute bioavailability of DZP after IN administration using this formulation was $33.45 \% \pm 12.36 \%$ and the $t_{\max }$ was $18.33 \pm 23.09 \mathrm{~min}$, which was twice longer than the $t_{\max }$ obtained after MDZ administration $(9.25 \pm$ $6.75 \mathrm{~min}$ ). The $t_{\max }$ values obtained in this study for diazepam is in agreement with Gizurarson, et al. [13], who achieved peak levels after $18 \pm 11 \mathrm{~min}$ in healthy humans. The difference between $t_{\max }$ values of DZP and 


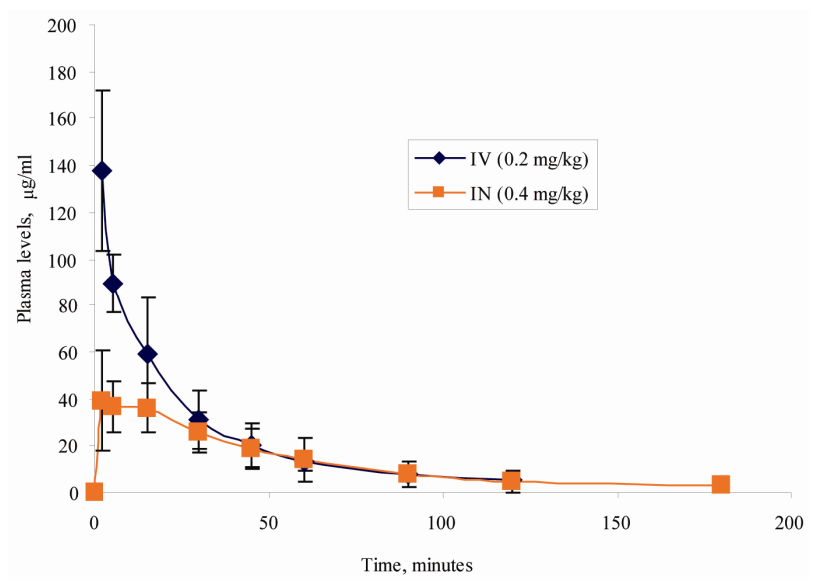

Figure 3. Pharmacokinetic profiles of midazolam after intravenous (solution, $0.2 \mathrm{mg} / \mathrm{kg}$ ) and intranasal (microemulsion, $0.4 \mathrm{mg} / \mathrm{kg})$ administrations to rabbits $(\mathrm{n}=4)$.

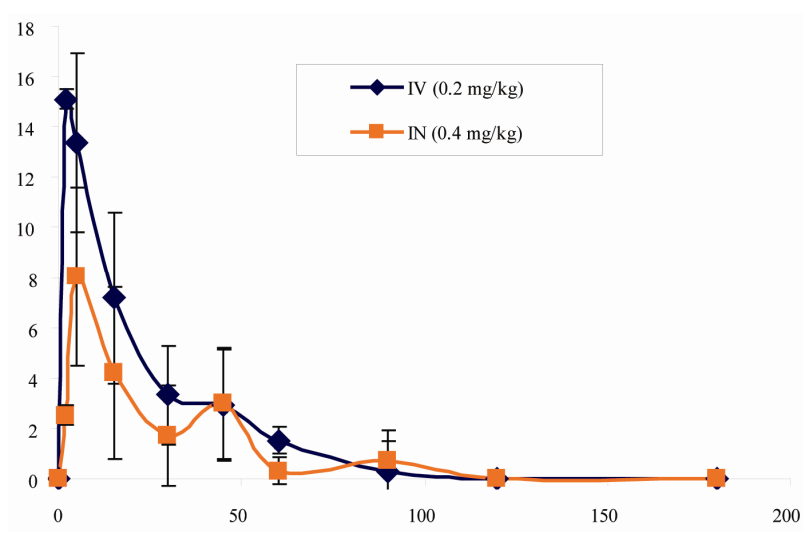

Figure 4. Pharmacokinetic profiles of diazepam after intravenous (solution, $0.2 \mathrm{mg} / \mathrm{kg}$ ) and intranasal (microemulsion, $0.4 \mathrm{mg} / \mathrm{kg}$ ) administrations to rabbits $(\mathrm{n}=3)$.

Table 2. Mean pharmacokinetic parameters of diazepam after $I V$ and $I N$ administration to rabbits $(\mathrm{n}=3)$.

\begin{tabular}{ccc}
\hline PK parameter & IV solution & IN microemulsion \\
& $0.2 \mathrm{mg} / \mathrm{kg}$ & $0.4 \mathrm{mg} / \mathrm{kg}$ \\
\hline $\mathrm{C}_{\max }(\mu \mathrm{g} / \mathrm{ml})$ & $18.63( \pm 3.76)$ & $8.40( \pm 3.00)$ \\
$t_{\max }(\mathrm{min})$ & 0 & $18.33( \pm 23.09)$ \\
${ }\left(\mathrm{min}^{-1}\right)$ & $0.0478( \pm 0.0124)$ & $0.0334( \pm 0.0171)$ \\
Elimination $t_{1 / 2}(\mathrm{~min})$ & $15.15( \pm 3.80)$ & $27.32( \pm 19.46)$ \\
$\mathrm{AUC}_{0-\infty}\left(\mu \mathrm{g} \cdot \mathrm{min} \cdot \mathrm{ml}^{-1}\right)$ & $383( \pm 93)$ & $270( \pm 143)$ \\
$\mathrm{AUC}_{0-\infty} /$ dose $\left(\mu \mathrm{g} \cdot \mathrm{min} \cdot \mathrm{ml}^{-1} \cdot \mathrm{D}^{-1}\right)$ & $1.91( \pm 0.46)$ & $0.67( \pm 0.36)$ \\
$\mathrm{F}_{\mathrm{A}}^{\mathrm{a}}(\%)$ & --- & $33.45( \pm 12.63)$ \\
\hline${ }^{\mathrm{a}} \mathrm{F}_{\mathrm{A}} \%=$ absolute bioavailability $=\left(\mathrm{AUC}_{0-\infty}{ }^{\mathrm{IN}} \times \mathrm{Dose}^{\mathrm{IV}}\right) \times 100 /\left(\mathrm{AUC}_{0-\infty}{ }^{\mathrm{IV}} \times\right.$ \\
Dose $\left.^{\mathrm{IN}}\right)$.
\end{tabular}

MDZ in our study was also noted by Ivaturi, et al. [7], who reported that $t_{\max }$ values in healthy volunteers after intranasal administrations were $28.8 \mathrm{~min}$ and $21.6 \mathrm{~min}$ for DZP and MDZ, respectively. Both benzodiazepines had comparable half-lives of elimination $\left(t_{1 / 2}\right)$, that is, $43.15 \pm 11.63 \mathrm{~min}(\mathrm{MDZ})$ vs. $27.32 \pm 19.46 \mathrm{~min}(\mathrm{DZP})$ after IN administration. Unlike $t_{1 / 2}$ values obtained in rabbits in the present study, the values obtained in humans according to the literature are significantly higher for MDZ and especially for DZP. Furthermore, the administration of DZP (IV and IN) to humans had a longer half-life than administration of MDZ. According to Ivaturi, et al. [7,12], the terminal half-life of DZP was 59.1 $\mathrm{h}$ [7] and $48.3 \mathrm{~h}$ [12], while that obtained for MDZ was $0.9 \mathrm{~h}$ after IV administration of $5 \mathrm{mg}$ of each drug. Wermeling, et al. [17] reported a half-life of $3.14 \mathrm{~h}$ after $5 \mathrm{mg}$ IV dose of MDZ to healthy volunteers, and Haschke, et al. [26] reported a half-life of $1.89 \mathrm{~h}$ after 1 mg IV dose of MDZ to human volunteers. Interestingly, $t_{1 / 2}$ values obtained in rats were much closer to our data than those obtained in humans, $55.4 \mathrm{~min}$ and $105.5 \mathrm{~min}$ for MDZ and DZP, respectively [27]. In light of the pharmacokinetic data obtained in our study, it can be concluded that: a) there is a species difference between rabbits (and rodents) and humans with regard to the elimination rate of benzodiazepines, but there is no apparent difference in the absorption process, resulting in a very short onset of time in both MDZ and DZP administrations; b) the longer time to reach peak plasma level $\left(t_{\max }\right)$ of DZP relative to MDZ may explain the clinical advantage in the use of midazolam over diazepam in the treatment of acute seizures [11].

The microemulsion system of this study provided a high drug concentration of $25 \mathrm{mg} / \mathrm{g}$ and (or even $50 \mathrm{mg} / \mathrm{g}$ ) compared with the $5 \mathrm{mg} / \mathrm{ml} \mathrm{MDZ-HCl}$ and DZP in plain solutions. We have also noted that a W/O macro-emulsion and a mixture of the oil and the surfactants, which had been formulated with the same components' ratio, provided high drug concentrations as well. Therefore, a separate study aimed to evaluate the pharmacokinetics of nasal MDZ using these formulations was carried out. The pharmacokinetic parameters are summarized in Table 3 and the plasma levels - time curves are illustrated in Figure 5. As shown, the resulted data were not much different from those obtained after IN administration of microemulsion. It should be emphasized that $\mathrm{W} / \mathrm{O}$ macro-emulsion formulation contained all ingredients of the $20 \%$ water-containing microemulsion except the co-surfactant. Surfactants mixture includes all ingredients except water. The ratio between the including ingredients were kept constant. This study has revealed that the surfactants' combination is more essential in solubilizing and carrying MDZ through the nasal mucosal membrane rather than the nanoparticulate structure of the formulation. It is postulated, therefore, that MDZ and DZP permeate into the systemic circulation via the nasal route by a mechanism involving entrapment within the micellar layers of the surfactants followed by a release into the 
Table 3. Mean pharmacokinetic parameters of midazolam after IN administration of two non-microemulsion formulations to rabbits $(n=4)$.

\begin{tabular}{ccc}
\hline PK parameter & IN Surfactant & IN Macroemulsion \\
& mixture $0.4 \mathrm{mg} / \mathrm{kg}$ & $0.4 \mathrm{mg} / \mathrm{kg}$ \\
\hline $\mathrm{C}_{\max }(\mu \mathrm{g} / \mathrm{ml})$ & $46.20( \pm 23.07)$ & $33.12( \pm 13.53)$ \\
$t_{\max }(\mathrm{min})$ & $3.50( \pm 1.73)$ & $5.00( \pm 0.0)$ \\
$\mathrm{z}\left(\mathrm{min}^{-1}\right)$ & $0.0149( \pm 0.0076)$ & $0.0204( \pm 0.0133$ \\
Elimination $_{1 / 2}(\mathrm{~min})$ & $55.02( \pm 23.57)$ & $52.32( \pm 40.02)$ \\
$\mathrm{AUC}_{0-\infty}\left(\mu \mathrm{g} \cdot \mathrm{min} \cdot \mathrm{ml}^{-1}\right)$ & $3154( \pm 1246)$ & $2736( \pm 919)$ \\
$\mathrm{AUC} C_{0-\infty} /$ dose $\left.^{-1} \cdot \mathrm{D}^{-1}\right)$ & $7.88( \pm 3.11)$ & $6.84( \pm 2.30)$ \\
$\left(\mu \mathrm{g} \cdot \mathrm{min}^{2} \mathrm{ml}^{-1} \cdot \mathrm{D}^{2}\right)$ & $44.00( \pm 7.97)$ & $40.46( \pm 16.23)$ \\
$\mathrm{F}_{\mathrm{A}}{ }^{\mathrm{a}}(\%)$ &
\end{tabular}

${ }^{\mathrm{a}} \mathrm{F}_{\mathrm{A}} \%=$ absolute bioavailability $=\left(\mathrm{AUC}_{0-\infty}{ }^{\mathrm{IN}} \times \mathrm{Dose}^{\mathrm{IV}}\right) \times 100 /\left(\mathrm{AUC}_{0-\infty}{ }^{\mathrm{IV}} \times\right.$ Dose $\left.^{\mathrm{IN}}\right)$.

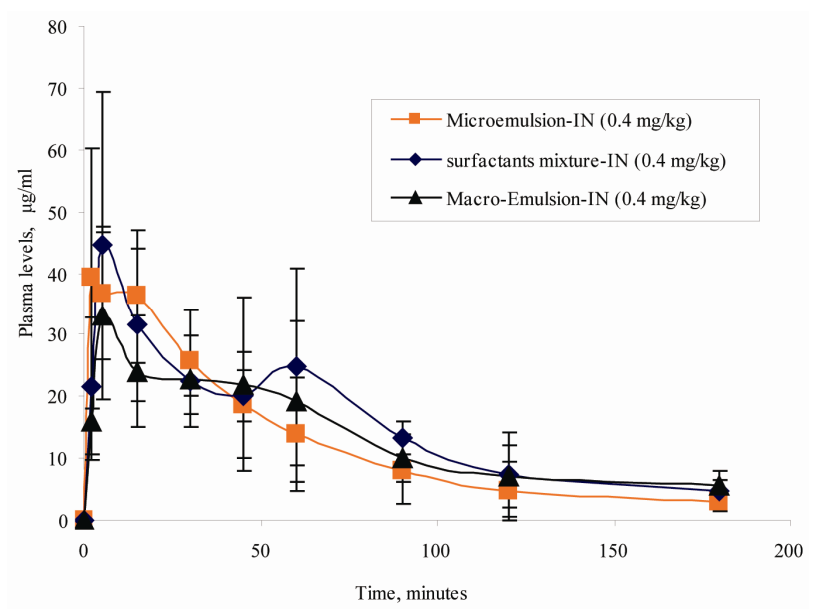

Figure 5. Pharmacokinetic profiles of midazolam after intranasal $(0.4 \mathrm{mg} / \mathrm{kg})$ administrations of three formulations to rabbits $(n=4)$ - a comparison between microemulsion, macroemulsion (both containing $20 \%$ aqueous phase) and surfactants mixture (without water). All formulations contain same components' ratios and $25 \mathrm{mg} / \mathrm{g}$ (2.5\% by weight) of the drug.

mucosa and transport. The possible entrapment and the surfactant-accompanying drug diffusion may explain why this method of nasal administration is apparently non-irritable.

\section{Conclusions}

Very few studies have reported the use of microemulsion for intranasal delivery of benzodiazepines. Just to make a point but not to limit, using PubMed with key words "intranasal", "microemulsion" and "diazepam", only three reports were found [28-30], while the combination of the two former keys with 'midazolam' yielded no publications. In comparison, over 200 studies on intranasal delivery of benzodiazepines have been published. With no intention of course to devaluate the current knowledge in the area, it may indicate that the potential of microemulsion technology has not yet been exploited enough for intranasal benzodiazepines. There is indeed a wide recognition that intranasal treatment is more available and easily administered even by the patient, in managing of seizure emergencies. However, patient compliance and tolerability are the major drawback in the development of intranasal midazolam and diazepam. In this paper, we present a new microemulsion that could be used as a safe and effective intranasal drug delivery system for midazolam or diazepam. An alcohol-free microemulsion formulation of a unique surfactant structure that does not also require an acidic $\mathrm{pH}$ to dissolve midazolam has been shown to have a potential of decreasing epithelial irritation while achieving the desired therapeutic effect. Apart from preventing nasal irritation, the microemulsion possesses two major advantages over plain solutions, one is a high solubilization capacity for MDZ base and DZP that exceeds their aqueous solubility and thus allows reduction in the application volume (to about $100-150 \mu \mathrm{g} /$ human nostril). The other advantage is that both benzodiazepines can be rapidly absorbed after nasal administration of the microemulsion to meet the emergency treatment purpose. The absolute bioavailability of MDZ and DZP in rabbits after application of the nasal microemulsion were $35.19 \%( \pm 11.83 \%)$ and $33.45 \%( \pm 12.63 \%)$, respectively. Although a considerable amount of drug is absorbed, the absorption rate is probably more important than the bioavailability in acute medical treatment, as already noted by Lindhardt, et al. [31]. The systemic absorption and tolerability of the microemulsion formulation in man remain to be established in future clinical studies.

\section{Acknowledgments}

The authors are grateful for the practical and professional assistance of Mr. Igor Krymberk and Ms. Lillia Shapiro at the Laboratory of Biopharmaceutics at the E.D. Bergmann Campus, Ben Gurion University of the Negev.

\section{References}

[1] J. McMullan, C. Sasson, A. Pancioli and R. Silbergleit, "Midazolam Versus Diazepam for the Treatment of Status Epilepticus in Children and Young Adults: A Meta-Analysis," Academic Emergency Medicine, Vol. 17, No. 6, June 2010, pp. 575-582. doi:10.1111/j.1553-2712.2010.00751.x

[2] C. Campo-Soria, Y. Chang and D. S. Weiss, "Mechanism of Action of Benzodiazepines on GABAA Receptors," British Journal of Pharmacology, Vol. 148, No. 7, August 2006, pp. 984-990.

[3] E. Costa, A. Guidotti and C. C. Mao, "Evidence for Involvement of GABA in the Action of Benzodiazepines: Studies on Rat Cerebellum," In: E. Costa and P. Greengard, Eds., Mechanism of Action of Benzodiazepines, Raven Press, New York, 1975, pp. 113-130. 
[4] W. Haefely, A. Kulcsar and H. Moehler, "Possible Involvement of GABA in the Central Actions of Benzodiazepines," Psychopharmacological Bulletin, Vol. 11, No. 4, October 1975, pp. 58-59.

[5] G. J. de Haan, P. van der Geest, G. Doelman, E. Bertram and P. Edelbroek, "A Comparison of Midazolam Nasal Spray and Diazepam Rectal Solution for the Residential Treatment of Seizure Exacerbations," Epilepsia, Vol. 51, No. 3, March 2010, pp. 478-482. doi:10.1111/j.1528-1167.2009.02333.x

[6] B. K. Alldredge, A. M. Gelb, S. M. Isaacs, M. D. Corry, F. Allen, S. Ulrich, M. D. Gottwald, N. O'Neil, J. M. Neuhaus, M. R. Segal and D. H. Lowenstein, "A Comparison of Lorazepam, Diazepam, and Placebo for the Treatment of Out-of-Hospital Status Epilepticus," New England Journal of Medicine, Vol. 345, No. 9, August 2001, pp. 631-637. doi:10.1056/NEJMoa002141

[7] V. D. Ivaturi, J. R. Riss, R. L. Kriel and J. C. Cloyd, "Pharmacokinetics and Tolerability of Intranasal Diazepam and Midazolam in Healthy Adult Volunteers," Acta Neurologica Scandinavica, Vol. 120, No. 5, November 2009, pp. 353-357. doi:10.1111/j.1600-0404.2009.01170.x

[8] C. O'Dell, S. Shinnar, K. R. Ballaban-Gil, M. Hornick, M. Sigalova, H. Kang and S. L. Moshe, "Rectal Diazepam Gel in the Home Management of Seizures in Children," Pediatric Neurology, Vol. 33, No. 3, September 2005, pp. 166-172. doi:10.1056/NEJMoa002141

[9] P. Mittal, R. Manohar and A. Rawat, "Comparative Study of Intranasal Midazolam and Intravenous Diazepam Sedation for Procedures and Seizures," Indian Journal of Pediatrics, Vol. 73, No. 11, November 2006, pp. 975-978. doi:10.1007/BF02758299

[10] E. Lahat, M. Goldman, J. Barr, T. Bistritzer and M. Berkovitch, "Comparison of Intranasal Midazolam with Intravenous Diazepam for Treating Febrile Seizures in Children: Prospective Randomised Study," British Medical Journal, Vol. 321, No. 7253, July 2000, pp. 83-86. doi:10.1136/bmj.321.7253.83

[11] M. Scheepers, B. Scheepers, M. Clarke, S. Comish and M. Ibitoye, "Is Intranasal Midazolam an Effective Rescue Medication in Adolescents and Adults with Severe Epilepsy?" Seizure, Vol. 9, No. 6, September 2000, pp. 417422. doi:10.1053/seiz.2000.0425

[12] V. D. Ivaturi, J. R. Riss, R. L. Kriel, R. A. Siegel and J. C. Cloyd, "Bioavailability and Tolerability of Intranasal Diazepam in Healthy Adult Volunteers," Epilepsy Research, Vol. 84, No. 2-3, April 2009, pp. 120-126. doi:10.1016/j.eplepsyres.2009.01.001

[13] S. Gizurarson, F. K. Gudbrandsson, H. Jonsson and E. Bechgaard, "Intranasal Administration of Diazepam Aiming at the Treatment of Acute Seizures: Clinical Trials in Healthy Volunteers," Biological \& Pharmaceutical Bulletin, Vol. 22, No. 4, April 1999, pp. 425-427.

[14] E. Bechgaard, S. Gizurarson and R. K. Hjortkjaer, "Pharmacokinetic and Pharmacodynamic Response after Intranasal Administration of Diazepam to Rabbits," Journal of Pharmacy and Pharmacology, Vol. 49, No. 8, August
1997, pp. 747-750.

doi:10.1111/j.2042-7158.1997.tb06105.x

[15] L. Li, S. Gorukanti, Y. M. Choi and K.H. Kim, "Rapidonset Intranasal Delivery of Anticonvulsants: Pharmacokinetic and Pharmacodynamic Evaluation in Rabbits," International Journal of Pharmaceutics, Vol. 199, No. 1, April 2000, pp. 65-76. doi:10.1016/S0378-5173(00)00373-2

[16] K. Lindhardt, S. Gizurarson, S. B. Stefansson, D. R. Olafsson and E. Bechgaard, "Electroencephalographic Effects and Serum Concentrations after Intranasal and Intravenous Administration of Diazepam to Healthy Volunteers," British Journal of Clinical Pharmacology, Vol. 52, No. 5, November 2001, pp. 521-527 doi:10.1046/j.0306-5251.2001.01486.x.

[17] D. P. Wermeling, K. A. Record, T. H. Kelly, S. M. Archer, T. Clinch and A. C. Rudy, "Pharmacokinetics and Pharmacodynamics of a New Intranasal Midazolam Formulation in Healthy Volunteers," Anesthesia \& Analgesia, Vol. 103, No. 2, August 2006, pp. 344-349. doi:10.1213/01.ane.0000226150.90317.16

[18] Z. N. Kain, L. C. Mayes, C. Bell, S. Weisman, M. B. Hofstadter and S. Rimar, "Premedication in the United States: A Status Report," Anesthesia \& Analgesia, Vol. 84, No. 2, February 1997, pp. 427-432. doi:10.1213/00000539-199702000-00035

[19] M. I. Ugwoke, R. U. Agu, N. Verbeke and R. Kinget, "Nasal Mucoadhesive Drug Delivery: Background, Applications, Trends and Future Perspectives," Advanced Drug Delivery Reviews, Vol. 57, No. 11, November 2005, pp. 1640-1665. doi:10.1016/j.addr.2005.07.009

[20] M. Bhattacharyya, V. Kalra and S. Gulati, "Intranasal Midazolam vs Rectal Diazepam in Acute Childhood Seizures," Pediatric Neurology, Vol. 34, No. 5, May 2006, pp. 355-359. doi:10.1016/j.pediatrneurol.2005.09.006

[21] P. D. Knoester, D. M. Jonker, R. T. Van Der Hoeven, T. A. Vermeij, P. M. Edelbroek, G. J. Brekelmans and G. J. de Haan, "Pharmacokinetics and Pharmacodynamics of Midazolam Administered as a Concentrated Intranasal spray. A Study in Healthy Volunteers," British Journal of Clinical Pharmacology, Vol. 53, No. 5, May 2002, pp. 501-507. doi:10.1046/j.1365-2125.2002.01588.x

[22] S. Bjorkman, G. Rigemar and J. Idvall, "Pharmacokinetics of Midazolam Given as an Intranasal Spray to Adult Surgical Patients," British Journal of Anaesthesia, Vol. 79, No. 5, November 1997, pp. 575-580.

[23] M. Holsti, B. L. Sill, S. D. Firth, F. M. Filloux, S. M. Joyce and R. A. Furnival, "Prehospital Intranasal Midazolam for the Treatment of Pediatric Seizures," Pediatric Emergency Care, Vol. 23, No. 3, March 2007, pp. 148153. doi:10.1097/PEC.0b013e3180328c92

[24] S. W. Provencher, "CONTIN: A General Purpose Constrained Regularization Program for Inverting Noisy Linear Algebraic and Integral Equations," Computer Physics Communications, Vol. 27, No. 3, September 1982, pp. 229-242. doi:10.1016/0010-4655(82)90174-6

[25] A. C. Sintov, H. V. Levy and S. Botner, "Systemic Deliv- 
ery of Insulin via the Nasal Route Using a New Microemulsion System: in vitro and in vivo Studies," Journal of Controlled Release, Vol 148, No. 2, December 2010, pp. 168-176. doi:10.1016/j.jconrel.2010.08.004

[26] M. Haschke, K. Suter, S. Hofmann, R. Witschi, J. Frohlich, G. Imanidis, J. Drewe, T. A. Briellmann, F. E. Dussy, S. Krahenbuhl and C. Surber, "Pharmacokinetics and Pharmacodynamics of Nasally Delivered Midazolam," British Journal of Clinical Pharmacology, Vol. 69, No. 6, June 2010, pp. 607-616. doi:10.1111/j.1365-2125.2010.03611.X

[27] A. Hoogerkamp, R. H. G. P. Arends, A. M. Bomers, J. W. Mandema, R. A. Voskuyl and M. Danhof, "Pharmacokinetic/Pharmacodynamic Relationship of Benzodiazepines in the Direct Cortical Stimulation Model of Anticonvulsant Effect," The Journal of Pharmacology and Experimental Therapeutics, Vol. 279, No. 2, November 1996, pp. 803-812.

[28] L. Li, I. Nandi and K. H. Kim, "Development of an Ethyl
Laurate-Based Microemulsion for Rapid-Onset Intranasal Delivery of Diazepam," International Journal of Pharmaceutics, Vol. 237, No. 1-2, April 2002, pp. 77-85. doi:10.1016/S0378-5173(02)00029-7

[29] P. Kaur and K. Kim, "Pharmacokinetics and Brain Uptake of Diazepam after Intravenous and Intranasal Administration in Rats and Rabbits," International Journal of Pharmaceutics, Vol. 364, No. 1, November 2008, pp. 27-35. doi:10.1016/i.ijpharm.2008.07.030

[30] S. Porecha, T. Shah, V. Jogani, S. Naik and A. Misra, "Microemulsion Based Intranasal Delivery System for Treatment of Insomnia," Drug Delivery, Vol. 16, No. 3, April 2009, pp. 128-134. doi: $10.1080 / 10717540802560381$

[31] K. Lindhardt, D. R. Olafsson, S. Gizurarson and E. Bechgaard, "Intranasal Bioavailability of Diazepam in Sheep Correlated to Rabbit and Man," International Journal of Pharmaceutics, Vol. 231, No. 1, January 2002, pp. 67-72. doi:10.1016/S0378-5173(01)00872-9 